\title{
Artigo
}

\section{A trajetória institucional da SUDENE: uma arena de cooperação federativa}

\author{
Luciléia Aparecida Colombo \\ Pós-Doutoranda no Programa de Pós-Graduação em Ciência Política da \\ UFRGS leiacolombo@gmail.com
}

\begin{abstract}
Resumo: $\bigcirc$ objetivo deste artigo é desenhar a trajetória institucional da Superintendência do Desenvolvimento do Nordeste (SUDENE), desde o seu fundamento, em 1959, até sua extinção, em 2001.' Como objetivos secundários, buscamos elucidar as motivações políticas que permearam o debate sobre a extinção, os atores políticos envolvidos, bem como as substituições a este modelo de desenvolvimento até então processado. A metodologia empregada é vasta, onde analisamos as Atas do Conselho Deliberativo da Sudene, jornais da época de fundação e extinção, bem como os programas elaborados pela SUDENE durante o regime militar. Estamos respaldados neste artigo pela teoria institucionalista, especialmente a vertente que prioriza o institucionalismo histórico. O presente artigo justifica-se, sobretudo, porque não se conhece, até o momento, um trabalho que tenha buscado traçar a trajetória institucional da Superintendência, sendo que tal proposta mostra-se, assim, original.
\end{abstract}

Palavras-chave: SUDENE; Desenvolvimento regional; Federalismo.

Abstract: The purpose of this article is to draw the institutional trajectory of Northeast Development Superintendency (SUDENE), since its foundation in 1959 until its extinction in 2001. As a secondary objective, we sought to elucidate the political motivations that permeated the debate over extinction, political actors involved, as well as replacements for this model of development hitherto processed. The methodology includes the Atas of the Deliberative Council of Sudene, newspapers at the time of foundation and extinction, as well as programs developed by SUDENE during the military regime. We are supported in this article by institutionalist theory, especially the aspect that prioritizes historical institutionalism. This Article is justified, particularly since we do not know, yet, a work traced the institutional trajectory of the Superintendent, and such proposal therefore shows up original.

Keywords: SUDENE; Regional Development; Federalism.

1 Este artigo é fruto de minhas considerações desenvolvidas na tese de doutorado, que tem por título: "Ascensão e queda de uma instituição: a Sudene no sistema federativo brasileiro". 


\section{Introdução}

\section{Federalismo e assimetrias regionais}

O federalismo brasileiro abarca grandes diferenças socioeconômicas entre os blocos regionais que compõem o território brasileiro. Desse modo, é considerado assimétrico2 em relação a essas condições, sendo possível verificar expressivas desigualdades entre as regiões que formam o bloco Norte e Nordeste e o restante da federação. Como bem definiu Elazar (1987), os elementos fundadores de todas as federações são os princípios da diferença e da diversidade. Assim, a assimetria constatada na federação brasileira, explicitadas neste trabalho, sobretudo em relação às diferenças econômicas entre as regiões, constituiu-se em objeto de preocupação de diferentes governos.

O termo "federalismo assimétrico" tem aparecido na literatura de forma recorrente. Ivo Duchacek o mencionou em 1970, quando devotou um capítulo inteiro sobre seus meios e implicações no texto intitulado: Comparative Federalism: the territorial dimension of politics. O autor identificou grandes disparidades, que denominou "ingredientes de poder", entre as unidades componentes da federação, que podem ser altamente politizadas em seus limites territoriais com diferenças linguísticas, culturais ou étnicas. Entretanto, observa Duchacek (1970) que se essas diferenças não forem reorganizadas na federação, podem ser altamente explosivas. Neste sentido, a federação serve como uma associação política de pequenas comunidades para preservar suas distintas identidades e separar organizações políticas, ao mesmo tempo que retém ligações econômicas, políticas e militares com o grande estado-nação.

De acordo com Burguess (2006), essas assimetrias podem ser de duas ordens: socioeconômica ou cultural-ideológica. Os fatores socioeconômicos têm, para este autor, intensa ligação com clivagens sociais e territoriais, pois as fraquezas de cada unidade constituinte confluem para a grande economia nacional; cada economia nacional, por

2 Apesar de o conceito de assimetria não ser algo novo, ele aparece na literatura de forma fragmentada, como ressalta Burguess (2006, p. 210): "The term 'assymmetrical federalism' has appeared in the mainstream literature at regular intervals but only in a fragmentary manner". William Livingston publicou, em 1952, um artigo intitulado: A Note on the Nature of Federalism, no qual identifica o reconhecimento da diversidade social como a fundação do espírito federal. Todos os demais autores federalistas reconhecem a presença das assimetrias federativas. Ronald Watts, em 2000, também dedicou parte de seu trabalho para a compreensão das assimetrias federativas no Canadá. E, como já assinalado aqui, Daniel Elazar reconheceu, em 1987, que a presença das assimetrias é parte integrante de todas as federações, em diversos países. 
sua vez, deve possuir um aparato para intervir nestas assimetrias, usando uma variedade de mecanismos de equalização fiscal federal. Tal fato observa-se claramente no Brasil, onde as economias dos estados pobres dependem da redistribuição de recursos federais, como uma maneira de contrabalançar as disparidades regionais. Por seu turno, os fatores cultural-ideológicos, como o próprio nome diz, referem-se a hábitos, costumes, convenções, que fazem parte das particularidades de cada federação e que também podem representar um problema, caso não sejam adequadamente acomodados no interior da federação.

Dentre várias outras maneiras de combater as assimetrias federativas, está a promoção do chamado federalismo cooperativo, conceito elaborado por Daniel Elazar (1984). O autor enfatiza os aspectos da negociação e da cooperação, reiterando uma conceitualização em que o federalismo aparece como uma associação voluntária, uma forma contratual de estados independentes com objetivos comuns. Ainda segundo o autor, o termo "federal" é derivado do latim foedus, que quer dizer acordo. Em geral, arranjos federais são parcerias estabilizadas e reguladas por um pacto, que reflete relações internas de um tipo especial de partilha, que prevalece entre os parceiros, baseado em um mútuo reconhecimento de cada membro na tentativa de promover uma unidade especial entre eles. No entanto, o modelo de Elazar (1987) não é capaz de explicar quais mecanismos institucionais seriam capazes de favorecer essa cooperação por parte dos entes federados.

O grande problema do tratamento político adequado das assimetrias federativas e, consequentemente, da diversidade reside no fato de que, como aponta Elazar (1987), por diversas vezes as soluções federais fracassam ao tentar eliminar a diversidade quando, na realidade, seria necessário apenas acomodá-la. Isso porque a própria preservação da estrutura federal prevê mecanismos para acomodação das heterogeneidades, não para tornar todas as unidades governamentais plenamente iguais e heterogêneas, mas para mantê-las, simplesmente, unidas. Fica claro, assim, que o princípio federalista já pressupõe a desigualdade, subproduto da diversidade.

Juntamente com o princípio da assimetria, um segundo princípio, conhecido como regionalismo, sempre permeou as relações federativas no Brasil. Aspásia Camargo (1999) afirma que em países como o nosso a dimensão institucional do federalismo só pode ser examinada à luz da relevância geopolítica e histórica do regionalismo. Segundo a 
autora, o regionalismo é um dos pilares mais importantes e decisivos para a compreensão dos conflitos e dos arranjos políticos que marcaram o Brasil a partir de 1930.

Segundo Castro (1992), em países internamente diferenciados, os problemas étnicos e culturais são recursos eficientes para tornar visível os conflitos desencadeados por um poder econômico e político desigual, não sendo, em si, desencadeadores de conflitos. Em contrapartida, na ausência de diferenças étnicas e culturais marcantes e na presença de desigualdades regionais importantes, como é o caso do Brasil, surge naturalmente a indagação sobre quais seriam os recursos possíveis de mobilização capazes de conduzir o descontentamento regional para a arena política nacional. Esses recursos têm sido exatamente aqueles vinculados ao regionalismo.

Vale destacar que embora sejam conceitos distintos, regionalismo e federalismo nem sempre são esferas separadas, podendo mesclar-se e trazer à tona a região3 como instância política. Uma região é uma fração estruturada do território, possuindo uma identidade que permite diferenciá-la de outras regiões. Essa personalidade regional possibilita a sua delimitação a partir da compreensão das especificidades que ela contém sendo, portanto, concreta, observável e delimitável. Segundo Castro (1992): "Como qualquer segmento do espaço, a região é dinâmica, historicamente construída e interage com o todo social e territorial. Portanto, suas características internas são determinadas e determinantes desta interação" (Castro, 1992, p. 33).

Partindo de tais premissas, o Nordeste pode ser compreendido, então, como um espaço político-administrativo, e o "Nordeste da SUDENE" como uma institucionalização de interesses comuns, organizados para vencer obstáculos históricos. Não é tão somente uma região-plano, idealizada para aplicação de um projeto de desenvolvimento; o Nordeste da SUDENE teve durabilidade no tempo, perpassando e convivendo, inclusive, com a mudança de regimes políticos. Essas características o tornam uma região construída historicamente e que contém elementos da complexa relação entre espaço, ideologia e política. A persistência das questões regionais induziu, também, à materialização das clivagens regionais. Como não temos diferenças étnicas, religiosas ou linguísticas capazes de oferecer perigo à integração do todo nacional, os problemas

3 Oliveira (1977) ressalta que o Nordeste como "região", tanto na opinião pública quanto nas políticas e programas governamentais, sofreu diversas alterações ao longo da história. Entretanto, a compreensão deste enquadramento ou, mais especificamente, dos limites territoriais dos estados que compõe a região Nordeste fornece elementos para a compreensão da própria formação político-econômica nacional e suas diferenciações. 
derivados do poder econômico desigual inter-regional sobressaíram ao longo do tempo, sendo levado ao cenário nacional o descontentamento regional.

A criação da SUDENE representou um avanço para o federalismo brasileiro ao propor um planejamento regional institucionalizado, com capacidade de projeção dos problemas regionais nordestinos para o centro político das decisões nacionais. Sua vinculação direta à Presidência da República denota a importância que passava a ter a partir de então. Mais do que isso, a SUDENE visava à superação da política localista da região, buscando diminuir o poder das oligarquias rurais e, ao mesmo tempo, fortalecer politicamente os governadores nordestinos. A composição do Conselho Deliberativo da Superintendência expressava essa preocupação e as decisões eram tomadas de forma consensual, com todos os governadores e representantes do Executivo Federal.

Grande parte das preocupações contidas nos objetivos da SUDENE estava em conexão direta com os trabalhos desenvolvidos pelo Grupo de Trabalho para o Desenvolvimento do Nordeste (GTDN), convocado por Juscelino Kubitscheck para estudar a região. Os principais objetivos do GTDN e que se tornaram, posteriormente, diretrizes da SUDENE podem ser resumidos, grosso modo, em quatro pontos principais: (1) criação de um centro de expansão manufatureira no Nordeste; (2) transformação da economia agrícola da faixa úmida, para garantir adequada oferta de alimentos nos centros urbanos; (3) transformação progressiva da economia nas zonas semiáridas para torná-las mais resistentes à seca e (4) deslocamento da fronteira agrícola do Nordeste por meio da incorporação de terras úmidas do Maranhão à economia regional. Neste sentido, lançavam-se as bases para uma espécie de "substituição de importações" na qual a industrialização visava à redução do desemprego, que o documento estimava ser entre 307 mil e 512 mil pessoas no Nordeste no ano de 1959.4

4 Assim como ocorreu no Brasil, com a criação SUDENE, outros países adotaram estratégias para a promoção do desenvolvimento regional. O caso mais conhecido foi o dos Estados Unidos, com a criação do TVA (Tennesse Vale Authority) em 1933, como parte do New Deal e que previa o planejamento com o intuito de promover o desenvolvimento de seis Estados dos EUA. Os objetivos eram amplos e envolviam obras para controle de enchentes, construção de usinas hidroelétricas, desenvolvimento do transporte rodoviário e marítimo, modernização da agricultura, modernização da indústria e do setor de serviços. Além da continuidade dos programas do TVA, foram criados novos programas para as bacias hidrográficas do país, o que ficou conhecido como Economic Development Area (EDA), além do programa especial para os Apalaches, em 1965. Consolidava-se, assim, o desenvolvimento regional nos Estados Unidos. Na Inglaterra, experiência semelhante ocorreu em decorrência da crise e estagnação das regiões mineradoras em contraste com a concentração industrial em Londres, 0 que trouxe à tona a "divisão norte-sul". O Governo daquele país criou então a Comissão Barlow, prevista para os anos 1937 a 1940, com o intuito de recuperar a expansão da indústria da região norte. Na Itália, novamente a diferença entre o Norte e o Sul do país representava uma ameaça ao Governo central especialmente após a redemocratização com o fim do fascismo. Em função disso, foi criada em 1950 a Cassa per II Mezzogiorno, ambiciosa política de industrialização para o Sul daquele país. Esta política introduziu os incentivos fiscais para a formação de capital, cujo mecanismo foi disseminado para outros 
No entanto, o Golpe Militar ocorrido em 1964, além de promover reestruturações profundas na sociedade brasileira e bloquear o desenvolvimento da nossa jovem experiência democrática, proporcionou à SUDENE cortes significativos em sua capacidade de implementar decisões. Cumpre destacar que a Superintendência não foi extinta naquele momento, resistindo a este período ditatorial. Sua extinção formal aconteceu somente em 2001, no governo de Fernando Henrique Cardoso.

Desse modo, traçamos a trajetória da instituição, buscando evidências que comprovem seu enfraquecimento ao longo do tempo e que nos levem ao entendimento das motivações que desencadearam em sua completa extinção no governo FHC. O recorte temporal relativamente extenso (de 1959, momento da fundação da SUDENE, até 2001, ano de sua extinção) nos forneceu elementos importantes para a explicação da mudança institucional processada na Superintendência. Além disso, esse recorte permite uma abordagem comparativa do comportamento da instituição desde o momento de sua criação até sua extinção.

\section{Os anos iniciais do período militar e as transformações na SUDENE}

O movimento político de 1964 promoveu alterações na SUDENE e novas medidas foram tomadas com relação ao Nordeste, as quais realinhavam os problemas econômicos, sociais e políticos ao projeto dos militares, num clima em que prevaleciam os grandes empreendimentos, caracterizando o chamado "Brasil Grande ou Brasil Potência".

O grupo majoritário da coalizão governista, os "sourbonistas", no qual se incluía o Presidente Castelo Branco, visava "arrumar a casa". Não vamos realizar uma ampla abordagem de como foi a transição do regime civil para o militar, uma vez que, além de não ser foco deste trabalho, diversos autores ${ }^{5}$ se encarregaram desta tarefa. O que

países, inclusive para o Brasil, na criação da SUDENE. Na França, a densidade demográfica em Paris e o esvaziamento do campo levaram a uma política de desconcentração produtiva e de reordenação do território por meio de investimentos de empresas estatais em regiões selecionadas e de um programa de infraestrutura, implementado a partir dos anos 1940. Em 1963, foi criada ainda neste país a Delegation Dámanagement Du Territorie (Datar), que previa uma rede de cidades, dotadas de investimentos industriais e equipamentos públicos, conhecidas como "metrópoles de equilíbrio". Após a consolidação destas experiências, foram desenvolvidos esforços teóricos interpretativos sobre a questão das desigualdades regionais, personificadas através de duas escolas do pensamento. A primeira ficou conhecida como Ciência Regional, inclusive com a criação da Regional Science Association, liderada por Walter Isard. A Ciência Regional enfatizava um conjunto de técnicas de análise regional, de custos de transporte e de mercados concorrenciais. Em contrapartida, a segunda linha de pensamento foi desenvolvida na França, por volta de 1935, por François Perroux, que desenvolveu o conceito de polos de desenvolvimento. Perroux tinha influências de Schumpeter, como em relação ao conceito de inovação trazido pelo clássico Teoria do Desenvolvimento Econômico.

5 Entre eles, Stepan (1988) \& Lamounier (1979, 1988, 1992). 
convém destacarmos é que, tomado o poder, os militares cercaram-se de um conjunto de medidas para sustentar o regime que então se instalou. Foram instaurados dois Atos Institucionais, o Al-2 e o Al-3. Em 1965, o Al-2 extinguiu os partidos e tornou indiretas as eleições para presidente e vice-presidente, sendo este Ato complementado pelo Al-3, que tornou também indireta a eleição para governador de estado. Rompeu-se, neste momento, definitivamente, qualquer aproximação do regime com o período pré-64 e instalou-se o regime militar.

Este novo regime foi alicerçado sobre a centralização de poderes nas mãos da Presidência da República, que se tornou o centro político do sistema. A partir de então, instalou-se o modelo federativo unionista autoritário que, como destaca Abrucio (2002), apoiou-se em três pilares: financeiro, administrativo e político. Pelo lado financeiro, os recursos concentravam-se no Executivo Federal, que tinha o arbítrio para repassá-los a estados e municípios. O Governo central também controlava a atuação administrativa nos três níveis de governo. Finalmente, o Executivo Federal controlava das eleições às governadorias, evitando assim oposição ao regime.

Com relação ao aspecto regional, o regime militar concentrou em sua órbita o planejamento, tirando poder da SUDENE e repassando para as novas instituições criadas. O rompimento da ordem democrática e o tratamento dado às questões sociais no pós-64 reduziram a importância política da SUDENE, retirando definitivamente suas propostas reformistas iniciais. A SUDENE perdeu o posto de ser vinculada à Presidência da República, sendo integrada ao recém-criado Ministério Extraordinário para a Cooperação dos Organismos Regionais (MECOR), transformado, posteriormente, em Ministério do Interior (MINTER). Celso Furtado foi obrigado a deixar o país, afastando-se também do trabalho empreendido anteriormente para desenvolvimento do Nordeste e, com o principal mentor afastado do cargo, abriu-se o precedente para que as forças políticas desagregadoras passassem novamente a fazer parte da instituição. Forças militares ocuparam cargos importantes no interior da Superintendência, principalmente em substituição aos governadores, no Conselho Deliberativo. Logo também foi organizada uma Comissão de Inquérito encarregada de apurar irregularidades supostamente cometidas pela administração anterior na SUDENE. Segundo Lima (2009), as investigações da comissão nada encontraram de concreto. 
Contudo, o principal golpe na SUDENE foi o corte no orçamento, reduzido abruptamente, o que transformou a Superintendência em um órgão de apoio financeiro e técnico a projetos nacionais. A lógica dos investimentos alterou-se, sendo que os recursos financeiros foram direcionados aos estados mais desenvolvidos da federação como, por exemplo, Pernambuco, Bahia e Ceará; iniciou-se uma fase federativa de cooperação apenas vertical, onde as desigualdades - antes apenas regionais - passaram então a ser, concomitantemente, interestaduais no Nordeste.

Porém, como ressalta Carvalho (1987), a ruptura com o antigo padrão de desenvolvimento, que tinha como pontos norteadores o diagnóstico do GTDN, não se processou de maneira abrupta. A autora em tela ressalta que houve uma espécie de sobrevida ao projeto inicial da SUDENE até o final da década de 1960, ao menos teoricamente, enquanto a prática se mostrava diferente. Isso porque as medidas preconizadas pelo GTDN e concretizadas através da SUDENE materializavam a preocupação com a Questão Nordeste. A sobrevida do projeto inicial da SUDENE, entre outras razões, deveu-se ao fato de que os militares não podiam ignorar os problemas da região, pois a questão do desenvolvimento nordestino estava na pauta governamental naquele momento mesmo com a mudança de regime político. Os baixos índices de desenvolvimento na região Nordeste foram agravados pela insurgência de uma nova seca, denominada "a seca do século", que se estendeu de 1979 até 1984 e que trouxe novamente a região para o palco das grandes discussões nacionais.

A sobrevida do Projeto SUDENE também se justificou porque os militares consideravam o projeto do GTDN como um dos mais consistentes para a região e também porque imediatamente após o golpe ressurgiu a questão agrária. Foi preciso estabelecer mecanismos imediatos de controle de agitação no campo que, como visto no capítulo anterior, exigiram um controle mais direto por parte do Estado. ${ }^{6}$ Com a ascensão dos militares houve o anúncio de que a revolução tinha sido feita para realizar as reformas necessárias ao lado do combate à corrupção e à "infiltração comunista". O fato é que, em meio à repressão, Castelo Branco preparava um projeto de Reforma Agrária que seria então transformado no Estatuto da Terra, encabeçado por Roberto Campos e aprovado pela Lei no 4.504/1964.

6 Nesse sentido, foi criada em 1962 a SUPRA (Superintendência da Reforma Agrária), no governo João Goulart, para conter a agitação no campo. Além disso, este presidente propôs antes do golpe diversas medidas de desapropriação a fim de que se realizasse uma reforma agrária no Nordeste. Com o golpe, Goulart foi deposto e seus projetos abandonados. 
No governo Castelo Branco, o cargo de superintendente foi entregue a João Gonçalves de Souza, um civil que tinha na questão agrária, bem como na revitalização da agricultura, o foco principal das intervenções federais. Além disso, a preocupação com a questão agrária não foi prioridade somente deste governo, mas de todo o período de 1964-1969, onde apaziguar o campo se impunha como o caminho seguro para dar estabilidade à economia nacional. Segundo o relato de Carvalho (1987), em 1964 houve uma reunião do MECOR, do Ministério da Indústria e Comércio, do Ministério do Trabalho e Previdência Social, da Presidência do IAA e da Superintendência da SUDENE, visando modernizar a agroindústria açucareira e buscando melhorar as condições de vida dos trabalhadores rurais. Todavia, mesmo com as declarações de Castelo Branco, a questão da posse da terra não foi resolvida e a SUDENE focou as atenções na modernização das atividades rurais e de setores complementares.

As medidas tomadas pelos militares para conter a agitação no campo foram um substitutivo da reforma, por meio de projetos de colonização, os chamados programas especiais. Além dos Programas Especiais foram criados o PIN (Programa de Integração Nacional) e o PROTERRA (Programa de Redistribuição de Terras e Estímulo à Agroindústria do Norte e Nordeste). Os Programas Especiais mais diretamente ligados à questão fundiária foram o POLONORDESTE e o Projeto Sertanejo.

Os Planos Diretores da SUDENE ${ }^{8}$ tiveram que se adaptar à nova sistemática de intervenção de um Estado centralizador. Segundo dados da Superintendência (1990), seguiram-se mais seis Planos Diretores, todos nacionais, sendo eles: 1) Três Planos Regionais de Desenvolvimento (PRD, para os períodos de 1972-1974, 1975-1979 e 1980-1985); 2) Para o período de 1986-1991 era previsto o I Plano Nacional de Desenvolvimento da Nova República - I PND/NR; 3) Uma Política de Desenvolvimento para o Nordeste, em 1986 e, finalmente, 4) Para os anos de 1988-1990, o I Plano Trienal de Desenvolvimento do Nordeste - I PTDN. A fim de melhorar a agricultura, as estratégias governamentais voltaram-se para o apoio na iniciativa privada; assim, a SUDENE foi transformada em um órgão de planejamento e fiscalização cujas tarefas foram descentralizadas e divididas com a iniciativa privada, grande executora dos projetos.

7 Posteriormente João Gonçalves de Souza foi substituído por Rubens Costa, no governo de Castelo Branco.

8 Otamar de Carvalho (1979) faz uma diferenciação em cada Plano Diretor elaborado pela Superintendência. Pela ordem cronológica, os planos da SUDENE foram os seguintes: I Plano Diretor (aprovado em 1961); II Plano Diretor (1963-1965); III Plano Diretor (1966-1968); IV Plano Diretor (1969-1973). 
No entanto, a mudança de regime político provocou várias alterações tanto na sociedade em geral como também na economia, que foi marcada por uma forte recessão. Segundo Carvalho (1988), nesse momento o sistema de incentivos da Sudene mostrou-se essencial para a atração de investimentos para o Nordeste. Era conhecido como um "socialismo às avessas", uma vez que o financiamento dos investimentos era privatizado, a fim de criar empresas industriais ou agrícolas no Nordeste. Portanto, em grande medida, como ressalta Carvalho (1987), a posição da SUDENE no período militar foi a de administrar e buscar ampliar os incentivos, inclusive com encontros com investidores, de analisar a viabilidade técnica dos projetos, aprovando-os e repassando os recursos para sua implantação.

A sistemática de aplicação destes incentivos financeiros favoreceu a implantação de grandes empreendimentos, não tendo qualquer influência sobre investimentos de empresas menores. Uma vez que os investidores eram ao mesmo tempo dedutores e aplicadores, a maioria dos empreendimentos era proveniente de quem detinha mais poder econômico. Nesta fase, a ênfase do Governo Federal voltou-se para a implantação do Complexo Petroquímico de Camaçari na Bahia, do Complexo Cloroquímico de Alagoas, do Complexo Industrial Portuário de Suape em Pernambuco, do Polo Siderúrgico do Maranhão, do Complexo Industrial de Base de Sergipe, do Polo Têxtil e de Confecções de Fortaleza no Ceará, do Complexo Agroindustrial do Médio São Francisco em Petrolina, do Polo de Fruticultura Irrigada do Vale do Açu em Rio Grande do Norte e diversos outros empreendimentos nas cidades nordestinas.

Modificou-se a maneira de elaborar as políticas de desenvolvimento regional e, como ressalta Oliveira (1977, p. 125), sobre a atuação da SUDENE, no regime militar:

Perde, pois, qualquer sentido continuar a falar de "economias regionais" no Brasil, e o fato de que a própria SUDENE continue a tocar uma música antiga, vem apenas em desabono do organismo de planejamento regional, que, por sinal, deixou de ter qualquer sentido de "planejamento".

Os resultados desses empreendimentos repercutiram tanto na economia e na sociedade quanto na política. Em boa medida, serviam para legitimar o novo regime e o novo pacto de poder. Uma vez que os problemas do Nordeste eram apresentados como decorrência do atraso e das disparidades inter-regionais de desenvolvimento, a 
industrialização, a multiplicação das fábricas, a modernização e os êxitos econômicos alcançados passaram a ser apresentados como condição básica e fundamental para a superação dessas condições. Nesse sentido, tais empreendimentos passaram a ser veiculados como provas do interesse e do esforço do Estado. Mais do que isso, representavam um acerto das suas políticas para a região e uma legitimação do discurso militar que salientava que diante de tão graves problemas no Nordeste caminhava-se agora para a sua resolução, propagando as realizações, o otimismo e a confiança no futuro de um "novo Nordeste" que já se configurava.

Entretanto, as críticas ao então modelo de desenvolvimento não tardaram a surgir. Havia uma espécie de indefinição e ambiguidade no novo governo, como ressalta Carvalho (1987), e uma fissura no bloco militar que assumiu o poder polarizada entre os "duros", com orientação nacionalista, e os da "Sorbonne", cujo objetivo era a integração da sociedade com o estrangeiro. Neste sentido, as orientações para o desenvolvimento também foram diferentes, em cada governo militar, mas tinham uma urgência comum: a questão agrária. Portanto, ao lado da facção repressiva, o grupo "Castelista" (19641967), com o Ministro Roberto Campos, tratou de propor medidas visando a uma transformação do setor agrícola, preconizando a realização de uma reforma agrária. Castelo Branco considerava que para a estabilidade do novo regime, a revitalização do campo era essencial a fim de conter agitações, preocupação que perpassou também o governo também de seu sucessor, Costa e Silva.

Na formação do governo Costa e Silva, a Superintendência foi entregue ao general Euler Bentes, que atuou diretamente com o general Albuquerque Lima, Ministro do Interior. Ambos os atores políticos pertenciam à chamada Ala Nacionalista das Forças Armadas, que tinha como pressupostos a soberania, a segurança e a integração da nação. No final de seu mandato, Costa e Silva foi responsável por aprovar o IV Plano Diretor da SUDENE (1969-1973), que trazia algumas concepções do GTDN, especialmente pela trajetória do Ministro Albuquerque Lima, que havia feito parte do Conselho Deliberativo do CODENO.

Os projetos de Costa e Silva apresentavam várias características dos demais governos militares, visando basicamente a: assegurar o crescimento da região, diminuir a desigualdade de renda entre o Nordeste e o Centro-Sul, manter investimentos em infraestrutura, criar empregos, ampliar a oferta de alimentos e melhorar os índices sociais. Isso 
tudo priorizando a agricultura, o abastecimento e os recursos humanos. Como ressalta Carvalho (1987), houve uma sobrevida ao projeto do GTDN durante este período procurando, contudo, superar o antigo modelo de desenvolvimento com mais inovações e benefícios.

Diversamente no período anterior, com os pressupostos da política regional sendo ditados em grande medida pelo diagnóstico do GTDN, os objetivos a serem perseguidos pela intervenção do Estado deixaram de estar centrados na redução das disparidades e no atendimento das necessidades e demandas de áreas consideradas como menos desenvolvidas e problemáticas. As dimensões e implicações sociais e políticas daquela intervenção e motivações como a preservação da unidade e segurança nacional, o alívio das tensões e a promoção de uma maior justiça social ou a obtenção de um desenvolvimento mais harmonioso e equilibrado, foram abstraídas ou se tornaram secundárias dentro das novas orientações.

Porém, a aprovação do IV Plano Diretor da SUDENE começou a se chocar com os objetivos nacionais do governo Costa e Silva, enfrentando pressões e oposições, especialmente diante do artigo que propunha a participação dos empregados nos lucros das empresas beneficiadas pelos incentivos da SUDENE. Essas determinações passaram a chocar-se com determinações do Ministério da Fazenda e do Planejamento, que possuíam outras diretrizes para o desenvolvimento nacional da política econômica federal.

O Ministério do Planejamento e Coordenação Geral começou a preparar o Plano Nacional de Desenvolvimento (PND), que cobria os anos de 1968-1970. O PND, além de ser trienal, entrava em vigor um ano antes da vigência do IV Plano Diretor da Sudene (1969-1973), o que tornava incompatível, portanto, os interesses regionais e os objetivos nacionais. Este impasse político acabou gerando as demissões, em 1969, de Albuquerque Lima e Euler Bentes, e novas reformulações da política de desenvolvimento regional foram feitas. A transição para os anos 1970 foi marcada pelo esforço de consolidar a industrialização do Nordeste não mais por um sistema planejado, nos moldes do antigo órgão, mas por meio do controle, pelo Governo Federal, da política de desenvolvimento regional, empreendida agora sob as vestes dos Planos Nacionais de Desenvolvimento.9

9 O planejamento ganhou espaço no regime militar com planos como o PAEG (Plano de Ação Econômica do Governo) e o Plano Decenal, no governo Castelo Branco. O Programa Estratégico de Desenvolvimento (PED) norteou a gestão Costa e Silva. O Programa de Metas e Bases para a Ação do Governo e o I Plano Nacional de Desenvolvimento Econômico e Social (I PND) foram a tônica do governo Médici, precedidos pelo II PND, durante o governo de Ernesto Geisel e o III PND, no governo do general Figueiredo. 


\section{Mudança institucional e futuro da SUDENE}

As instituições são formadas para ter durabilidade no tempo, como já ressaltamos anteriormente; no entanto, segundo Goodin (1996, p. 25), elas não são eternas e imutáveis, mas as regras internas, os constrangimentos formais e informais que circundam uma instituição fazem com que a mudança seja dificultada. Todavia, as motivações para que ocorram mudanças institucionais são variadas e, ainda segundo o autor, podem ocorrer por três motivações: acidente, evolução ou por intenção:

There are, roughly speaking, three basic ways in which social institutions (or human societies more generally) might arise and change over time. First, might occur by accident. There are, on this account, no forces of natural or social necessity at work, no larger causal mechanisms driving things. What happens just happens. Second, social change might be a matter of evolution. As in biological analogues from wich these models borrow, the initial variation might have occurred utterly at random, as a matter of pure accident and happenstance. Third, social change might be a product of intentional intervention. That is to say, the change might be the product of the deliberate interventions of purposive, goal-seeking agents. Those agents might be either isolated individual or organized groups.

North (1993, p. 38) salienta que a mudança geralmente ocorre devido a uma atitude revolucionária, mas mesmo assim é incremental, não acontece abruptamente:

The process of change is overwhelmingly incremental. (...) Therefore, except in case of gridlock, institutional change will occur at those margins considered most pliable in the context of the bargaining power of interested parties. The incremental change may come from a change in the rules via statute or legal change. For informal constraints there may be a very gradual withering away of an accepted norm or social convention or the gradual adoption of a new one as the nature of the political, social, or economic exchange gradually changes.

A mudança verificada na SUDENE, no período militar, foi conduzida pela mudança de regime, intencional, portanto, que retirou as prerrogativas democráticas da sociedade, rompendo com antigas instituições, como abordamos neste artigo. Foi um golpe nas prerrogativas elaboradas por Furtado e em toda a estrutura que havia sido montada para a superação do atraso nordestino. Todavia, mesmo antes do período militar, o projeto inicial de Furtado encontrava dificuldade para consolidar-se. Em relação ao período 
pós-1964, podemos apontar três fatores que indicam mudanças na SUDENE. Em primeiro lugar, a Superintendência foi rebaixada do status de um órgão ligado à Presidência da República e passou a estar atrelada ao Ministério do Interior e à SEPLAN. Este motivo já indica claramente que o governo, naquele momento, não intencionava manter os poderes conferidos à instituição por Kubitscheck. As acusações de Furtado pertencer ao partido comunista também contribuíram, no plano moral, para a desvalorização da Superintendência e para a descrença de que ela podia auxiliar no desenvolvimento do Nordeste.

Em segundo lugar, ao enfraquecer a SUDENE, o regime militar trouxe à tona antigas instituições que estiveram fortemente atreladas às oligarquias rurais e que historicamente desviaram recursos financeiros para auxiliar os latifundiários, a exemplo do DNOCS. Quase todos os Programas Especiais elaborados durante este período contavam com a execução ou o planejamento do Departamento Nacional de Obras Contra as Secas. Este foi um claro indicativo de que o atendimento a estas elites rurais foi, de alguma maneira, contemplado.

Em terceiro lugar, os planos elaborados pelos militares, especialmente aqueles atrelados aos Programas Especiais, desconsideraram todos os estudos anteriormente realizados pelo GTDN e pela própria SUDENE, que afirmavam que o problema do Nordeste não eram as secas, mas sim o subdesenvolvimento. Que mesmo nas áreas úmidas, a situação de miséria era enorme. Todavia, esta descoberta foi desconsiderada pelos militares, que voltavam toda a atenção para programas que buscavam a modernização da agricultura e da agroindústria, aplicando, essencialmente, medidas corretivas para o fenômeno das secas, retrocedendo à "fase hidráulica" de intervenção estatal.

Porém, como indicamos neste artigo, apesar de todos os fatores acima descritos e, principalmente, de a SUDENE ter sua importância reduzida enquanto uma instituição planejadora do desenvolvimento, o projeto inicial do GTDN e de Furtado teve uma sobrevida no período militar. Não inteiramente, obviamente, mas algumas considerações contidas no projeto do GTDN ainda foram cumpridas nos governos de Castelo Branco e Costa Silva, sendo rompidos, definitivamente, os princípios furtadianos no Governo Médici. Esta sobrevida pode ser explicada também por North (1993), que afirma que a mudança institucional que se processa de maneira revolucionária altera as regras formais das instituições, mas as informais levam um tempo maior para se modificarem 
completamente, pois estão contidas nos modelos mentais dos indivíduos. Além disso, as instituições eficientes, ao longo do tempo, adquirem estabilidade, o que faz com que sua estrutura normativa seja preservada da ameaça da mudança:

Revolutionary change, however, is never as revolutionary as its rhetoric would have us believe. It is not just that the power of ideological rhetoric fades as the mental models of the constituents confront their utopian ideals with the harsh realities of post-revolutionary existence. Formal rules may change overnight, but informal constraints (wich may be the result of deep-seated cultural in-heritance because they have traditionally resolved basic exchange problems) results in tensions that typically get resolved by some restructuring of the overall constraints - in both directions - to produce a new equilibrium that is far less revolutionary than the rhetoric (NORTH, 1993, p. 39).

Além disso, apesar de o regime militar ter alterado profundamente a sociedade brasileira, produzindo uma grande concentração de poder na órbita federal, a SUDENE permaneceu. Ela não foi extinta, ao contrário do que esperava o próprio Furtado, conforme seu discurso em seu livro de memórias A fantasia desfeita (1989). Obviamente, a SUDENE continuou atuando sem as prerrogativas de outrora, mas a não extinção é uma prova da solidez institucional da Superintendência, naquele momento. A extinção viria anos mais tarde, em 2001, provando, portanto, que este processo foi gradual:

A maioria das mudanças institucionais, no entanto, caracteriza-se por ser um processo incremental, ao invés de totalmente reconstrutivo ou destrutivo. Uma vez estabelecidas, as instituições tendem a desenvolver uma vida própria. O processo de criação institucional é um processo que tende também a aumentar a sobrevivência das instituições. Grande parte das instituições formais são estabelecidas por lei. (...) Isto torna a dissolução de uma instituição deste tipo algo difícil - embora isto não seja impossível. Todavia, ela permanece suscetível à mudança, sendo esta produto, por sua vez, de decisões institucionais internas que alteram, em geral de forma sutil, a distribuição de recursos (LEVI, 1991, p. 91).

A não extinção da SUDENE no período militar advém do fato de que, segundo Thelen e Steinmo (1992), as instituições não operam em um vacum, mas criam caminhos que permitem interagir com o grande contexto socioeconômico no qual estão instaladas. Assim, a SUDENE não foi extinta porque os militares sabiam que o Nordeste continuava a destoar em níveis de desigualdade quando comparado com as demais 
regiões e que a exclusão da Superintendência, naquele momento, poderia causar um desgaste ainda maior à região. Todavia, os resultados que a SUDENE apresentava não eram condizentes com o que Furtado desejou inicialmente.

Embora admitam que as instituições possam ser resistentes às mudanças, Thelen e Steinmo (1992) destacam que as mudanças institucionais acontecem de forma sutil, em resposta às alterações no contexto socioeconômico ou político. Esta incrementalidade no processo de mudança institucional leva ao entendimento de que a direção da mudança é determinada pela path dependency. E dentro deste conceito de path dependency, há a noção de "momento crítico" (critical juncture). Segundo Fernandes (2002, p. 85):

Momento crítico é definido como um período de significativa mudança, que normalmente ocorre em distintos caminhos por diferentes países (ou outras unidades de análise), e que é hipotetizado para produzir legados distintos. O momento crítico é uma situação de transição política e/ou econômica, vivida por um ou vários países, estados, regiões, distritos ou cidades, caracterizada por um contexto de profunda mudança, seja ela revolucionária ou realizada por meio de reforma institucional.

E ainda:

O tempo de duração desse momento crítico pode ser de anos ou até décadas, durante os quais o processo de mudança que se inaugura deixa um legado que conduz os políticos a fazerem escolhas e tomarem decisões sucessivas ao longo do tempo, visando à reprodução desse legado (ou path dependency) (FERNANDES, 2002, p. 86).

Collier e Collier (1991) ampliam este debate e apontam que o momento crítico pode acontecer devido a uma clivagem ou crise, que é uma situação na qual ocorre um rearranjo das forças políticas e sociais, levando à emergência de uma situação revolucionária ou de reforma, que deixará um legado. Todavia, existe um fim para esse legado que deve inevitavelmente ocorrer em algum ponto, sendo importante para uma análise descobrir e localizar os pontos de descontinuidade e autodestruição do objeto que se analisa.

Isso posto para nossa análise, consideramos que o momento crítico pelo qual passou a SUDENE aconteceu durante o regime militar, especificamente no governo do general Médici. A partir daí, nossas constatações levam-nos a acreditar que aos poucos a 
Superintendência foi se esfacelando, não conseguindo mais retroceder ao projeto inicial de Furtado. Sua extinção em 2001 foi então fruto desta grande mudança institucional ocorrida ou, mais especificamente, deste momento crítico.

\section{Conclusão}

Buscamos, neste artigo, abordar a trajetória da SUDENE, a partir da teoria do institucionalismo histórico, mostrando que as primeiras alterações promovidas durante o regime militar foram decisivas, criando um processo de path dependency, esfacelando aos poucos a Superintendência. Esta nossa hipótese foi comprovada porque, mesmo depois da mudança de sistema político, com a redemocratização do país, não houve uma revitalização da instituição. Ao contrário: a Constituição Federal de 1988 reservou algumas prerrogativas para garantir o apoio à superação da desigualdade regional, mas não promoveu, em contrapartida, o apoio à revitalização das instituições responsáveis pelo planejamento regional.

O Governo Federal adotou uma postura mais distante das questões regionais, restringindo-se ao cumprimento de repasses financeiros por meio dos Fundos Constitucionais. Estados e municípios permaneceram com um papel duplo: ora dependentes deste repasse dos Fundos, ora buscando, por conta própria, investimentos privados por meio de isenções tributárias. A descentralização foi a grande protagonista desse processo, concedendo autonomia para os entes federados que passaram então a utilizar de suas prerrogativas para promover por conta própria o crescimento das atividades produtivas em seus territórios.

O período posterior aos anos 1990 enalteceu novas orientações na maneira de pensar a questão regional, com uma revalorização do local e do chamado desenvolvimento sustentável. Alterou-se o padrão desenvolvimentista do período anterior e valorizou-se o "novo paradigma de desenvolvimento sustentável". Tal ideia coadunava-se com os princípios adotados por instituições internacionais como a ONU e o Banco Mundial. Porém, apesar de tentar se reerguer politicamente, a SUDENE não logrou resultados satisfatórios, tendo que se readaptar a este novo modelo de intervenção do Estado surgido nos anos 1990, sem ter, contudo, como garantir um espaço institucional de articuladora deste processo. $O$ desenho institucional adquirido pela Superintendência nos 
anos posteriores à Constituição de 1988 manteve a inércia perante um reaparelhamento das políticas regionais, caracterizado pelos novos pressupostos do desenvolvimento sustentável e pelo desenvolvimento endógeno.

O quadro federativo desenhado nos anos 1990 pautou-se pela reorientação das políticas públicas federais, voltadas para a redução das desigualdades econômicas regionais, fator que repercutiu desfavoravelmente na cooperação entre os governos estaduais no Nordeste. O padrão de cooperação entre os entes subnacionais dependia em grande parte da articulação da União. Uma vez que o Governo Federal não se envolveu diretamente com as questões regionais, essa cooperação esgarçou-se. Isso porque não temos, no Brasil, uma tradição política capaz de estabelecer arranjos cooperativos interestaduais horizontais sem a participação do poder público federal na ação regional.

Assim, após a redemocratização do Brasil, a SUDENE revelou-se uma instituição paralisada diante de novas opções que se configuravam para o próprio Nordeste. 0 desenho institucional inicial da SUDENE foi se alterando, chegando em 2001 praticamente com todas as suas atribuições bastante confusas, sendo que no caso particular da instituição as mudanças mais radicais iniciaram-se no regime militar, especificamente no governo Médici. Isso prova que no caso particular da Superintendência a path dependency teve um papel primordial nas mudanças institucionais processadas a partir de então, pois do regime militar até a sua extinção a Superintendência veio em uma linha declinante constante.

Não é sem razão que foram exatamente os governadores de estado os primeiros atores a paulatinamente abandonarem a Superintendência. Isso porque estes atores políticos já não tinham mais sua principal fonte que os unia no Conselho Deliberativo, ou seja, os recursos financeiros da Superintendência. Com a constante redução do Fundo (FINOR), tornava-se desinteressante colaborar com as medidas impostas pela SUDENE, sendo mais fácil buscarem financiamentos por conta própria. Em tal situação, aplicam-se as considerações de Olson (1999), o qual salienta que mesmo que todos os membros de um grupo desejem racionalmente a maximização de seu bem-estar pessoal, eles não agirão de forma coletiva, a menos que haja alguma coerção para forçá-los a cooperar. Esta coerção pode ser um incentivo, que não esteja diretamente vinculado ao objetivo comum, oferecido à parte e individualmente, com a condição de que estes indivíduos ajudem a arcar com o ônus envolvido na consecução do objetivo coletivo. 
Portanto, a partir do momento em que não era vantajoso para os governadores atuarem coletivamente em prol da manutenção da SUDENE, eles abandonaram as reuniões do Conselho Deliberativo e foram barganhar, diretamente com o Executivo Federal, os recursos de que necessitavam para se desenvolverem. O próprio Fundo da Sudene, o FINOR, deixou de ser um atrativo para a cooperação voluntária dos governadores de estado, sendo alvo, inclusive, de diversas denúncias de corrupção, que culminou com a montagem da CPI do FINOR.

O que se conclui, portanto, é que o desenho institucional da Superintendência em 2001 não garantia sua eficácia enquanto uma instituição encarregada de articular interesses estaduais. Portanto, a atitude de Fernando Henrique Cardoso foi de promover a anulação de sua atuação, a qual vinha se processando desde 1964.

\section{Referências}

ABRUCIO, F. L. Os Barões da Federação. Os governadores e a redemocratização brasileira. São Paulo: Hucitec, 2002.

BURGUESS, M. Between a rock and a hard place: the Russian federation in comparative perspective. In: ROSS, C. \& CAMPBELL, A. (Eds.). Federalism and local politics in Russia. Routledge, 2009, pp. 25-53.

Comparative federalism. Theory and practice. New York: Routledge, 2006.

CAMARGO, A. Do federalismo oligárquico ao federalismo democrático. In: PANDOLFI, D. Repensando o Estado Novo. Rio de Janeiro: Ed. Fundação Getúlio Vargas, 1999. p. 39-51.

CARVALHO, I. M. M. O Nordeste e o regime autoritário. São Paulo: Hucitec-Sudene, 1987.

CARVALHO, O. A economia política do Nordeste: secas, irrigação e desenvolvimento. Rio de Janeiro: Campus, 1988.

. Desenvolvimento regional: um problema político. Rio de Janeiro: Campus, 1979.

CASTRO, I. E. Solidariedade territorial e representação. Novas questões para o pacto federativo nacional. Revista Território, vol. 1, 1997.p. 33-41.

- O mito da necessidade - discurso e prática do regionalismo nordestino. Rio de Janeiro: Editora Bertrand Brasil, 1992.

COLLIER, D.; COLLIER, R. Shaping the political arena: critical junctures, the labor movement, and regime dynamics in Latin America. Princeton: Princeton University Press, 1991. 
DUCHACEK, I. D. Comparative federalism: the territorial dimension of politics. New York: Holt, Rinehart and Winston, 1970.

ELAZAR, D. American federalism: a view from the states. Third Edition: New York, Harper \& Row, 1984.

. Exploring Federalism. Tuscaloosa: The University of Alabama Press, 1987. . Federal system of the world. New York: Stockton Press, 1994. . Self-Rule/Shared Rule: federal solutions to the midle east conflict. Lanham: University Press of America, 1984.

. The role of Federalism in Political Integration. In: ELAZAR, D. J. (Org.). Federalism and Political Integration. Tel Aviv: Israel, Turtledove Pusblishing, pp. 13-57, 1979.

ELAZAR, D.; KINCAID, J. The convenant connection: from federal theology to modern federalism. Lanham: Lexington Books, 1994.

FERNANDES, A. S. A. Path dependency e os estudos históricos comparados. São Paulo: BIB, no 53, 2002, p. 79-102.

GOODIN, R. E. Institutions and Their Design. In: GOODIN, R. E. (ed.). The theory of institutional design. Cambridge: Cambridge University Press, 1996. p. 1-125.

LAMOUNIER, B. Brazil: inequality against democracy. In: DIAMOND, L. et alii (eds.). Democracy in developing countries in Latin America. Boulder, Ed. Lynne Reinner, 1989. . Estrutura institucional e governabilidade na década de 90. In:VELLOSO, J.P.R. (Org.). O Brasil e as reformas políticas. Rio de Janeiro: José Olympio, 1992. O "Brasil autoritário" revisitado: o impacto das eleições sobre a abertura. In: STEPAN, A. (Org.). Democratizando o Brasil. Rio de Janeiro: Paz e Terra, 1988. O discurso e o processo. Da distensão às opções do regime brasileiro. In: RATTNER, H. (org.). Brasil 1980. Caminhos alternativos do desenvolvimento. São Paulo, Brasiliense, 1979.

LEVI, M. Uma lógica da mudança institucional. Dados - Revista de Ciências Sociais. Rio de Janeiro, vol. 34, n. 1, 1991. p. 79-99.

NORTH, D. Autobiography. The Bank of Sweden Prize in Economic Sciences in Memory of Alfred Nobel, 1993. . Epilogue: economic performance through time. In: ALSTON, L.; EGGERTSSON, T.; NORTH, D. (Ed.). Empirical studies in institutional change. Cambridge: Cambridge University Press, 1998. 
. Institutional change: a framework of analysis. In: SJOSTRAND, S. E. Institutional change

- theory and empirical findings. New York: A. E. Sharpe, 1993.

Institutions, institutional change and economic performance (Political Economy of

Institutions and Decisions). Cambridge: Cambridge University Press, 1990.

Institutions, transaction costs, and the rise of merchant empires. In: TRACY, J. D.

(ed.). The political economy of merchant empires, state power and world trade 1350-1750.

Cambridge: Cambridge University Press, 1997 (1ed. 1991).

Structure and change in Economic History, Norton, New York, 1981.

Structure and performance: the task of economic history. Journal of Economic Literature, 16, 1978.

The economic growth of the United States 1790-1860. New York:WW Norton \& Company, 1966. (Originalmente publicada em 1961, Prentice Hall).

. Understanding the process of Economic Change. Princeton: Princeton University Press, 1999.

THELEN, K. \& STEINMO, S. Historical Institutionalism in comparative politics. In: THELEN, K.; STEINMO, S.; LONGSTRETH, F. Structuring políticas. Historical institutionalism in comparative analysis. Cambridge: Cambridge University Press, 1992. p. 1-27.

OLIVEIRA, F. A. Crise, reforma e desordem do Sistema Tributário Nacional. Fev. 1992. 210 f. Tese (Livre Docência) - Departamento de Economia, UNICAMP, Campinas, 1992.

. A economia brasileira: crítica à razão dualista. São Paulo: Brasiliense, 1975. (Seleções Cebrap 1.)

. A economia da dependência imperfeita. Rio de Janeiro: Ed. Graal, 1984. Elegia para uma (Re)ligião. SUDENE, Nordeste, planejamento e conflitos de classe. Rio de Janeiro: Editora Paz e Terra, 1977.

. Quem tem medo da governabilidade? São Paulo: Novos Estudos Cebrap, no 41, mar. 1995. p. 61-77.

OLSON, M. A lógica da ação coletiva. Os benefícios públicos e uma teoria dos grupos sociais. São Paulo: EDUSP, 1999.

STEPAN, A. Authoritarian Brazil: origins, policies, and future. New Haven: Yale University Press, 1973. Second hardcover printing, 1975. Yale paperback, sixth printing, 1985. (Ed.). Democratizando o Brasil. Rio de Janeiro, Paz e Terra, 1988. Modern multi-national democracies: transcending a Gellnerian Oxymoron. In: HALL, 
T\&P A trajetória institucional da SUDENE: uma arena de cooperação federativa

J. A. (org.). The state of the nation: Ernest Gellner and the Theory of Nationalism. Cambridge: Cambridge University Press, 1998.

. Para uma nova análise comparativa do federalismo e da democracia: federações que restringem ou ampliam o poder do Demos. Dados, vol. 42, n. 2, 1999, p. 197-251. 